\title{
Effect of imperfect detection on the estimation of niche overlap between two forest dormice
}

\author{
Chiara Paniccia ${ }^{(1)}$, \\ Mirko Di Febbraro(1), \\ Ludovico Frate ${ }^{(1)}$, \\ Lorenzo Sallustio ${ }^{(2-3)}$, \\ Giovanni Santopuoli ${ }^{(2)}$, \\ Tiziana Altea ${ }^{(4)}$, \\ Mario Posillico ${ }^{(5-6)}$, \\ Marco Marchetti ${ }^{(2)}$, \\ Anna Loy ${ }^{(1)}$
}

\begin{abstract}
Quantification of niche overlap represents an important topic in several aspects of ecology and conservation biology, although it could be potentially affected by imperfect detection, i.e., failure to detect a species at occupied sites. We investigate the effect of imperfect detection on niche overlap quantification in two arboreal rodents, the edible dormouse (Glis glis) and the hazel dormouse (Muscardinus avellanarius). For both species, we used Generalized Linear Mixed Models (GLMM) to estimate the occurrence probability and Occupancy Models (OM) to calculate occurrence and detection probabilities. By comparing these predictions through niche equivalency and similarity tests, we first hypothesised that methods correcting for imperfect detection (OM) provide a more reliable estimate of niche overlap than traditional presence/ absence methods (GLMM). Furthermore, we hypothesised that GLMM mainly estimate species detectability rather than actual occurrence, and that a low number of sampling replicates provokes an underestimation of species niche by GLMM. Our results highlighted that GLMM-based niche overlap yielded significant outcomes only for the equivalency test, while OM-based niche overlap reported significant outcomes for both niche equivalency and similarity tests. Moreover, GLMM occurrence probabilities and OM detectabilities were not statistically different. Lastly, GLMM predictions based on single sampling replicates were statistically different from the average occurrence probability predicted by GLMM over all replicates. We emphasized how accounting for imperfect detection can improve the statistical significance and interpretability of niche overlap estimates based on occurrence data. Under a habitat management perspective, an accurate quantification of niche overlap may provide useful information to assess the effects of different management practices on species occurrence.
\end{abstract}

Keywords: Occupancy Models, Generalized Linear Mixed Models, Forest Management, Niche Overlap sional hypervolume, consisting of a range of abiotic and biotic variables, wherein a species is able to persist indefinitely in the absence of competition.

Concerns on how global change will influence niche dynamics in evolutionary and
(1957) is the space bounded by an n-dimen-

(1) Envix-Lab, Dipartimento di Bioscienze e Territorio, Università degli Studi del Molise, c.da Fonte Lappone, I-86090 Pesche, IS (Italy); (2) Centro di Ricerca per le Aree Interne e gli Appennini (ArlA), Dipartimento di Bioscienze e Territorio, Università degli Studi del Molise, c.da Fonte Lappone, I-86090 Pesche, IS (Italy); (3) CREA Research Centre for Forestry and Wood, v.le Santa Margherita 80, I-52100 Arezzo (Italy); (4) Coordinamento Territoriale Carabinieri per l'Ambiente, Parco Nazionale “Abruzzo-Lazio-Molise”, Pescasseroli, AQ (Italy); (5) Reparto Carabinieri Biodiversità Castel di Sangro, Centro Ricerche Ambienti Montani, Via Sangro, 45-67031. Castel di Sangro, AQ (Italy); (6) Consiglio Nazionale delle Ricerche, Istituto di Biologia Agroambientale e Forestale, v. Salaria km 29.300, I-00015 Montelibretti, RM (Italy)

@ Mirko Di Febbraro (mirkodifebbraro@gmail.com)

Received: Jan 24, 2018 - Accepted: May 01, 2018

Citation: Paniccia C, Di Febbraro M, Frate L, Sallustio L, Santopuoli G, Altea T, Posillico M, Marchetti M, Loy A (2018). Effect of imperfect detection on the estimation of niche overlap between two forest dormice. iForest 11: 482-490. - doi: 10.3832/ifor2738-011 [online 201807-18]

Communicated by: Massimo Faccoli community contexts, highlight the growing need for robust methods to quantify niche differences between or within taxa (Broennimann et al. 2012). During the last decade, statistical approaches have been developed allowing to compare species niches in a gridded environmental space (Warren et al. 2008, Broennimann et al. 2012). As a consequence, the estimation of niche overlap has become an important tool for investigating ecological requirements of invasive species (Gregory \& MacDonald 2009), relative abundance distributions (McGill et al. 2007), species coexistence (Gregory \& MacDonald 2009), evolutionary diversification (Araya et al. 2011) and conservation strategies (Russo et al. 2015). However, specific factors were shown to affect estimates of niche overlap. For instance, recent studies highlighted how niche overlap quantification may yield misleading results depending on the grain size (Kirchheimer et al. 2016) and the geographical scale (Russo et al. 2015) used to perform the analysis. Among other factors, imperfect detection, i.e., failure to detect a species at occupied sites was shown to affect niche estimation itself. For instance, 
predictions of species distribution through species distribution modelling (SDM), which are based on quantifying realized niche by means of the spatial (geographic) distribution of species across a study area (Raes 2012), may be underestimated if not accounting for imperfect detection (Rota et al. 2011, Lahoz-Monfort et al. 2014). In light of this evidence, investigating which bias could be introduced when quantifying overlap of two niches that are already affected by imperfect detection, represents an intriguing research topic.

Niche estimation and modelling typically relies on presence/absence or presence/ background data (Lahoz-Monfort et al. 2014). However, these data could be biased by the fact that species (both animals and plants - Chen et al. 2013) often remain undetected, making imperfect detection a serious issue in species surveys (Lahoz-Monfort et al. 2014, Guillera-Arroita 2017), and a major source of bias in wildlife distribution studies (MacKenzie et al. 2002). Unless a suitably large sampling effort is invested at surveyed locations, imperfect detection will result in the recording of false $a b$ sences in presence/absence data, potentially leading to biased conclusions and incorrect conservation actions (MacKenzie et al. 2002, Green et al. 2011). Many studies demonstrated that detectability varies among species, over time, and among habitats, and there may be serious consequences when this variability is ignored (Guillera-Arroita 2017). The occurrence of a species could be easy to prove, but species absence and non-detection can be often confounded, especially in case of species with low detectability (MacKenzie et al. 2002, Mackenzie \& Royle 2005).

A popular approach was proposed to overcome this problem by explicitly accounting for imperfect detection when quantifying species distribution (Macken- zie \& Royle 2005, Bailey et al. 2014). Hence, the so-called "occupancy models" are based on the detection history at sites and the proportion of sites where the species is detected, jointly modelling the processes describing where the species occurs and its detection at occupied sites (MacKenzie et al. 2002). In recent years, several studies highlighted the importance of explicitly accounting for imperfect detection when modelling species distribution (Rota et al. 2011, Lahoz-Monfort et al. 2014), though its effect on the quantification of niche overlap among species have been surprisingly overlooked. We aimed at filling this gap by evaluating the effect of imperfect detection on the quantification of niche overlap between two sympatric forest rodents. Specifically, we aimed at testing the following hypotheses:

- $\mathrm{H}_{1}$ : the probability of occurrence corrected for imperfect detection provides a more reliable estimate of niche overlap than predictions from traditional presence/absence methods;

- H2: predictions of occurrence probability derived from traditional presence/absence methods reflects the species detectability rather than its actual occurrence pattern;

- H3: a low number of sampling replicates in traditional presence/absence methods causes an underestimation of species niche.

The three hypotheses respectively focused on niche overlap between species $(\mathrm{H} 1)$, between modelling methods $\left(\mathrm{H}_{2}\right)$ and among sampling replicates $\left(\mathrm{H}_{3}\right)$. We targeted the analyses to two arboreal rodents: the edible dormouse (Glis glis) and the hazel dormouse (Muscardinus avellanarius), occurring sympatrically in a Central Apennines deciduous forest.

Although both species are strictly forest dependent, they exhibited different eco-

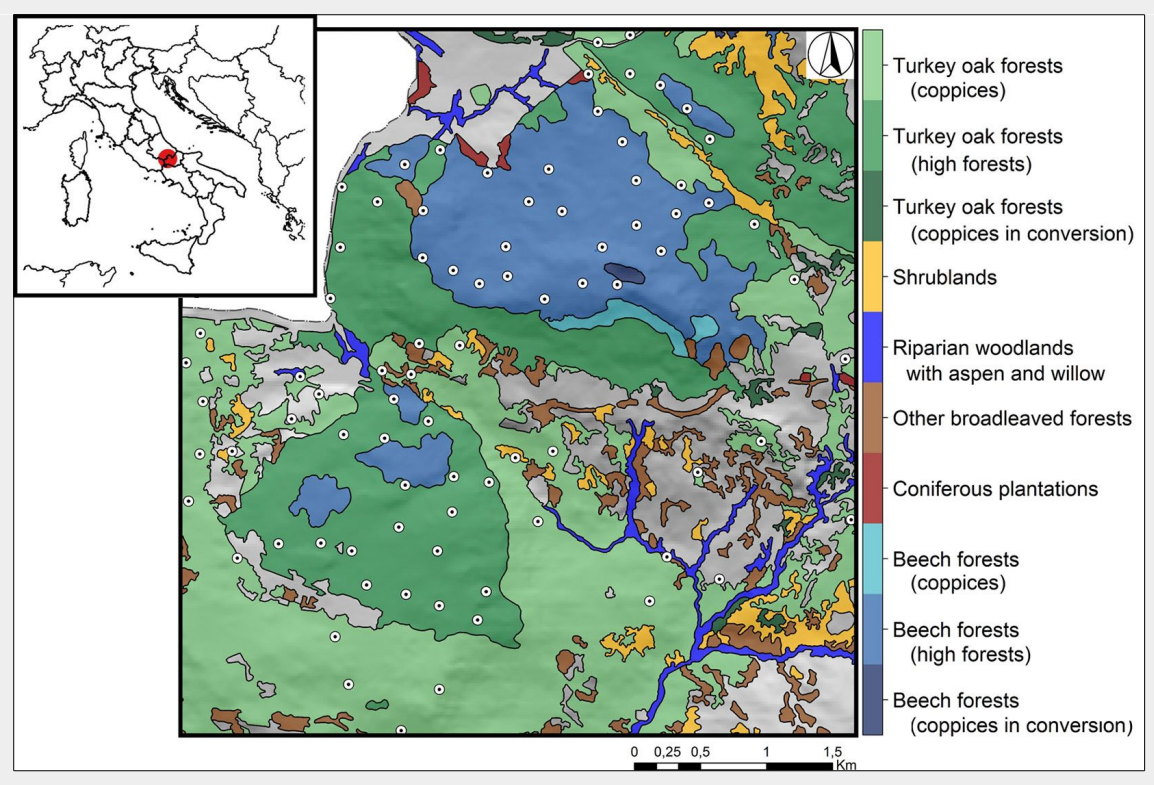

Fig. 1 - Map of the study area with sampling plots location. logical preferences with regard of forest characteristics (Capizzi et al. 2002, Panchetti et al. 2007) therefore representing ideal candidate species for a niche comparison study. The two species were surveyed with a sampling design addressed to provide both occurrence and detection probabilities (MacKenzie et al. 2002). Fine scale environmental covariates were then measured at each sampled plot and related to both occurrence and detectability.

\section{Materials and methods}

\section{Study area}

The study area is located in Central Apennines (Molise, Italy; $41^{\circ} 43^{\prime} \mathrm{N}, 14^{\circ} 06^{\prime} \mathrm{E}-$ Fig. 1), with an elevation ranging from 650 to $1300 \mathrm{~m}$ a.s.l.

The area covers approximately $18 \mathrm{~km}^{2}$ and it is mainly dominated by European beech (Fagus sylvatica L.) and Turkey oak (Quercus cerris L.) forests (Vizzarri et al. 2015), with different ownership, forest structures (i.e., coppices and high forests) and management objectives (i.e., timber harvesting, biodiversity conservation, hydrogeological protection etc.). The climate is classified as "temperate", with a mean annual precipitation of $1100 \mathrm{~mm}$ and a mean annual temperature of $8.6{ }^{\circ} \mathrm{C}$ (Blasi et al. 2005).

According to Amori et al. (2008), the study area hosts 25 small mammal species, including 14 rodents (order Rodentia, families Cricetidae, Gliridae, Muridae and Sciuridae) and 11 insectivores (order Eulipotyphla, families Erinaceidae, Soricidae and Talpidae), most of which (ca. 58\%) are listed in the Appendix III of the Bern Convention, in the Annex IV of 357/97/EC Habitats Directive or are protected by the Italian law 157/1992.

\section{Dormice occurrence sampling}

A total of 83 sampling plots were randomly located in the study area with a minimum distance of $200 \mathrm{~m}$ (mean nearest neighbour distance $=316 \pm 111 \mathrm{~m}$ ), in order to guarantee the independence of data based on the average home range size of the target species (Bright \& Morris 1991, Bright \& Morris 1992, Mortelliti et al. 2009). A nest box and a hair-tube were installed at each site (see Appendix 1 in Supplementary material). Sampling plots were checked for species presence/absence at 15 days intervals during the pre-hibernation period from the end of August until mid-October 2013 (Panchetti et al. 2007, Amori et al. 2008) for a total of four sampling replicates. Specifically, nest boxes were considered occupied either when individuals, nests, food remains or droppings were detected inside the box (Bright et al. 1994). Species presence at hair-tubes was determined by analysing hair samples found inside the tubes (for further details on the hair identification protocol, see Appendix 1 in Supplementary material). 
Forest parameters estimation and selection

A set of 12 dendrometric and typologicalstructural forest parameters were measured at each sampling plot following the Italian National Forest Inventory protocol (Gasparini \& Tabacchi 2011 - see also Appendix 2). In particular, dendrometric attributes were measured for all the living trees with a Diameter at Breast Height $(\mathrm{DBH}) \geq 7.5 \mathrm{~cm}$, considering circular plots of $13 \mathrm{~m}$ radius. Forest attributes related to deadwood were also quantified within the same circular plots (Lombardi et al. 2008). Typological-structural parameters including forest category, forest management and stand age were attributed according to the regional forest type and age maps (Vizzarri et al. 2015, Frate et al. 2016). Numerical covariates were standardized and sub-selected to avoid multicollinearity, considering a Variance Inflation Factor lower or equal to 10 (Zuur et al. 2010). This procedure led to a final set of seven forest predictors that were included in the subsequent analyses (Tab. 1).

\section{Modelling framework}

The modelling framework proceeds through three steps: (1) investigate the statistical relationships between species presence/absence and forest covariates through Generalized Linear Mixed Models (GLMM) and Occupancy Models (OM); (2) calculate the niche overlap between the two target species starting from the values of occurrence probability predicted by both modelling approaches; (3) quantify, for both species, the degree of niche similarity between GLMM and occupancy predictions, and by GLMM and detectability predictions, respectively.

\section{Generalized linear mixed models}

To investigate the statistical relationship between species occurrence and forest variables, we applied GLMM (McCullagh \& Nelder 1989) implemented in the "Ime4" package (Bates et al. 2015) of R statistical language ver. 3.4.0 ( $R$ Development Core Team 2018). GLMM proved useful when re- peated measurements are made on the same statistical units (i.e., longitudinal studies), therefore violating the independence of sampling units (Zuur et al. 2013, Johnson et al. 2015). The presence/absence data detected at each site during the four sampling replicates were used as response variable. We started from a full model including, as fixed effect terms, all the seven forest covariates (allowing both linear and quadratic relationships for the continuous ones), along with an interaction term with forest management (Tab. 1). Besides, we considered the sampling replicate as random effect. Specifically, we allowed the model to change its intercept according to the sampling replicate to take into account non-independence of data between different sampling of the same sites. We then applied a variable selection procedure allowing to compare models with all the possible combinations of the starting covariates and random effect terms. The "dredge" function in the R package "MuMIn" (Barton 2018) was used for model selection, ranking the candidate models according to their AICC (Burnham \& Anderson 2002). To account for uncertainty in model selection, we used a model averaging approach (i.e., we averaged all models within two $\triangle \mathrm{AICC}$ of the top model - Burnham et al. 2011, Nakagawa \& Freckleton 2011). The goodness-of-fit of the models was assessed by calculating the conditional and marginal coefficients of determination for GLMM (R_GLMM ${ }^{2}$ - Nakagawa et al. 2013).

Conditional $\mathrm{R} \mathrm{GLMM}^{2}$ is interpreted as the variance explained by both fixed and random factors (i.e., the entire model), whereas marginal R_GLMM ${ }^{2}$ refers to variance explained by the fixed factors (i.e., excluding the random effect - Nakagawa et al. 2013).

\section{Occupancy models}

This statistical approach consists of two hierarchically coupled sub-models, one governing the true state of sites (presence/ absence) and the other governing the observations (detection/non-detection - Mac-
Kenzie et al. 2002). OM can correct for imperfect detection due to false absences (i.e., failure to detect a species that is present at the site - MacKenzie et al. 2002), which represents a major source of bias in wildlife distribution studies (MacKenzie et al. 2002, Mackenzie \& Royle 2005). We applied a single-season, singlespecies model (MacKenzie et al. 2002) to compute the probability of occurrence (occupancy, $\psi$ ) and the probability of detecting the species (detectability, $p$ ), using the R package "unmarked" (Fiske \& Chandler 2011). In this case, we used the detection history of each species per site, i.e., the sequence of presences/absences over the complete survey period (four replicates), as response variable in the model. Similarly to GLMM, we started from a full model including all the seven forest covariates (allowing both linear and quadratic relationships for the continuous ones), along with an interaction term with forest management. Following Mortelliti et al. (2015), we split the variable selection procedure in two steps: (1) the detection probability was modelled as a function of different combinations of forest predictors, keeping the occupancy as constant and retaining the best subset of variables in the subsequent step; (2) the selection procedure was repeated simultaneously including both occupancy and detectability, while including, for the latter, only the variables combinations selected in step 1. As for GLMM, we averaged all models within $\triangle A I C C \leq 2$ from the top model. The goodness-of-fit of each model was measured using the Nagelkerke's pseudo- $R^{2}$ (Nagelkerke 1991). Predicted values of occurrence probability (from GLMM), $\psi$ and $p$ (from OM) were projected over the study area by spatializing the predictors selected in the topranked models (i.e., models within $\triangle \mathrm{AICC} \leq$ 2). Further details on the spatialization procedure are provided in Appendix 3 (Supplementary material).

\section{Niche overlap}

For both species, we ran the niche overlap analyses considering the following pa-

Tab. 1 - Explanatory variables used for GLMM and OM.

\begin{tabular}{|c|c|c|c|}
\hline Forest parameter & Type & Levels & Description \\
\hline \multirow{2}{*}{ Forest category (F_cat) } & \multirow{2}{*}{ Categorical } & Beech forest & \multirow{2}{*}{ Category of forest defined by its composition } \\
\hline & & Turkey oak forest & \\
\hline \multirow{3}{*}{ Forest management (F_man) } & \multirow{3}{*}{ Categorical } & Coppice with standard & \multirow{3}{*}{ Prevalent silvicultural system adopted } \\
\hline & & Coppice in conversion to high forest & \\
\hline & & Mature high forest & \\
\hline Tree species richness (SR) & Continuous & - & Number of tree species $(n)$ \\
\hline Tree density (T_density) & Continuous & - & Mean number of trees per hectare $\left(n \mathrm{na}^{-1}\right)$ \\
\hline $\begin{array}{l}\text { Mean of the trees' heights } \\
\text { (Mean_height) }\end{array}$ & Continuous & - & Average height of trees $(\mathrm{m})$ \\
\hline$\sigma^{2}$ Height (Stdev_height) & Continuous & - & Standard deviation of trees heights (m) \\
\hline Stand basal area (Basal_area) & Continuous & - & $\begin{array}{l}\text { The cross-sectional area of the tree stems } \\
\text { measured at breast height }\left(\mathrm{m}^{2} \mathrm{ha}^{-1}\right)\end{array}$ \\
\hline
\end{tabular}




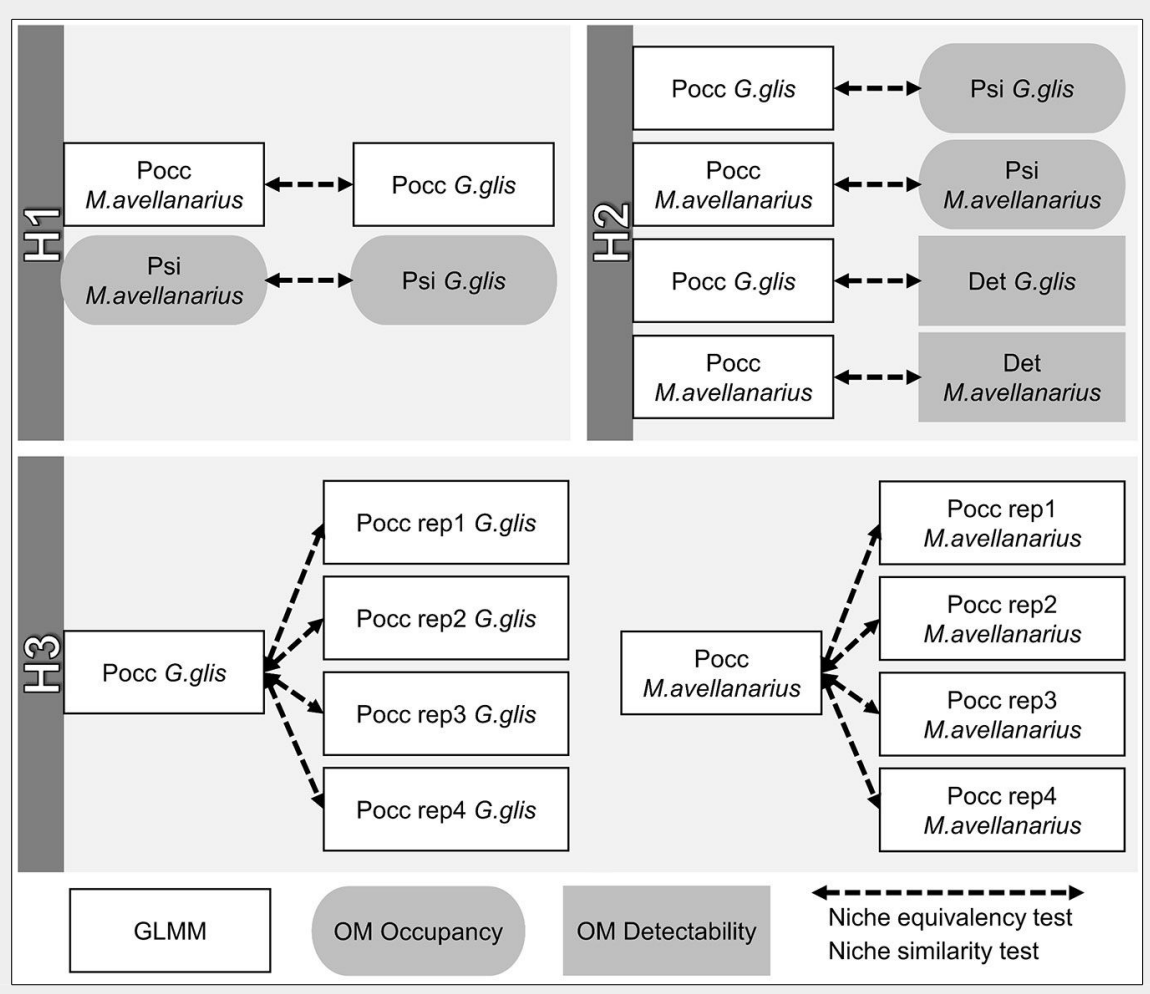

Fig. 2 - Flowchart of the niche overlap analysis implemented to test the three study hypotheses. White rectangles with black borders refer to occurrence probability values predicted by GLMM, grey rectangles with rounded borders indicate occupancy values predicted by $\mathrm{OM}$ and grey rectangles with squared borders indicate detectability values predicted by OM. Dashed arrows refer to niche equivalency and similarity tests used to compare the predictions.

rameters: $P_{\text {occ }}$ (average values of occurrence probability predicted by GLMM along all of the four replicates), $P_{\text {occ }}$ rep $i$ (occurrence probability predicted by GLMM for the $i$-th sampling replicate); Psi (occurrence probability predicted by $\mathrm{OM}$ ), Det (detection probability predicted by $\mathrm{OM} \overline{)}$. The flowchart of the methodological sequence followed to implement niche overlap analyses is depicted in Fig. 2.

To test $\mathrm{H} 1$, we performed the following niche overlap tests: $P_{\text {occ }}$ Gglis vs. $P_{\text {occ }} M a-$ vellanarius and Psi_Gglis vs. Psi_Mavellanarius. Then, we compared $\mathrm{P}_{\text {occ }}$ vs. Psi and $P_{\text {occ }}$ vs. Det for both species to test $\mathrm{H}_{2}$. Lastly, we tested $\mathrm{H} 3$ by calculating $\mathrm{P}_{\text {occ }}$ vs. $P_{\text {occ }}$ rep $i$, for both species and the four sampling replicates, separately. All the niche overlap tests are shown in Fig. 2.

Analysis of niche overlap between the two species was carried out using the analytical framework proposed by Broennimann et al. (2012) and recently adopted in different studies (Russo et al. 2015). Within this framework, the environmental space is defined by the axis of occurrence probabilities predicted by GLMM and OM for the two species. The output of such models comprises a single vector of predicted occurrence probabilities derived from complex combinations of functions of original environmental variables; the niche overlap is analysed along this gradient of predic tions (Broennimann et al. 2012). Niche overlap was computed in terms of Schoener's D (Schoener 1970), a metric that ranges from o (no overlap) to 1 (complete overlap).

We performed niche equivalency and similarity tests sensu Warren et al. (2008). The first test evaluates if the two species are identical (null hypothesis) in their niche space by using their exact locations and not including the surrounding space. The second also accounts for the differences in the surrounding environmental conditions and assess if the two species are more different than expected by chance. In particular, similarity between niches was tested in both directions, i.e., the amount of species 1 niche included in species 2 niche, and vice versa, following Broennimann et al. (2012). All the procedures were performed using the R package "ecospat" (Broennimann et al. 2017).

\section{Results}

Throughout the duration of the study, we reported 31 detections of $G$. glis at 27 of 83 sampling plots and 31 detections of $M$. avellanarius at 16 of 83 sampling plots (further details are provided in Tab. S1, Supplementary material). In GLMM, model selection procedure identified 15 top-ranked models for $G$. glis and three for M. avellanarius out of 3136 candidate models. Both species showed high values of conditional $\mathrm{R} \mathrm{GLMM}^{2}$ (G. glis: mean $=0.523$, SD $=$
$0.065 ;$ M. avellanarius: mean $=0.640, \mathrm{SD}=$ 0.006). Conditional R GLMM ${ }^{2}$ were always higher than marginal ones, indicating that the inclusion of the random effect systematically improved the models goodness-offit (Tab. S2). Occurrence of G. glis was predominantly explained by stand basal area (15 models) through a direct relationship. In addition, eight out of 15 top-ranked models predicted higher occurrence probabilities at increasing tree density values and in Turkey oak stands (Tab. S2, Fig. 3b). For $M$. avellanarius, mean tree height and interaction between tree density and forest management were the most important variables, resulting inversely related with species occurrence in all the top-ranked models. In addition, standard deviation of tree height and forest category were retained in more than a half of the top-ranked models, predicting higher occurrence probabilities in forests with high variability in tree heights and beech stands (Tab. S2, Fig. 3C).

In OM, the final model set included eight top-ranked models for $G$. glis and two for M. avellanarius out of 3136 candidate models. Goodness-of-fit statistics for the topranked models reported a mean pseudo- $\mathrm{R}^{2}$ equal to $0.370(S D=0.033)$ for $G$. glis and to $0.549(S D=0.030)$ for $M$. avellanarius (Tab. S3 in Supplementary material). For G. glis, both occupancy and detectability were directly related with stand basal area in all the top-ranked models. Six out of eight models also included forest management, predicting higher occupancy values in high forests and coppices in conversion rather than in coppices. Besides, mean tree height was retained in four models, always showing a direct relationship with the occurrence probability ( $\psi-$ Tab. S3, Fig. 3e). For M. avellanarius, occupancy was predominantly explained by standard deviation of tree heights, showing an inverse relationship in both top-ranked models. In addition, tree density and forest category were retained in half of the top-ranked models, predicting higher occupancy values in dense forests and beech stands (Tab. S3, Fig. 3f). Finally, M. avellanarius detectability was mainly explained by mean and standard deviation of tree height and tree density (Tab. $\mathrm{S}_{3}$ in Supplementary material). Maps of predicted detectability for the two species show overall higher values of $p$ for M. avellanarius (mean $=0.192, \mathrm{SD}=0.041$ ) than for $G$. glis (mean $=0.154$, SD $=0.004$; Fig. 4). For both species, GLMM predicted lower values of occurrence probability ( $G$. glis: mean $=0.104, \mathrm{SD}=0.083 ; M$. avellanarius: mean $=0.114, S D=0.201$ ) than probability values corrected by detectability under $\mathrm{OM}(\psi, \mathrm{G}$. glis: mean $=0.599, \mathrm{SD}=$ 0.163 ; $M$. avellanarius: mean $=0.504, \mathrm{SD}=$ 0.337 - Fig. S1).

As for niche overlap tests, GLMM's

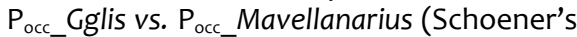
$D=0.41-$ Fig. 3a) showed significant outcomes only for the equivalency test. On the other hand, niche overlap computed on OM's Psi_Gglis vs. Psi_Mavellanarius 


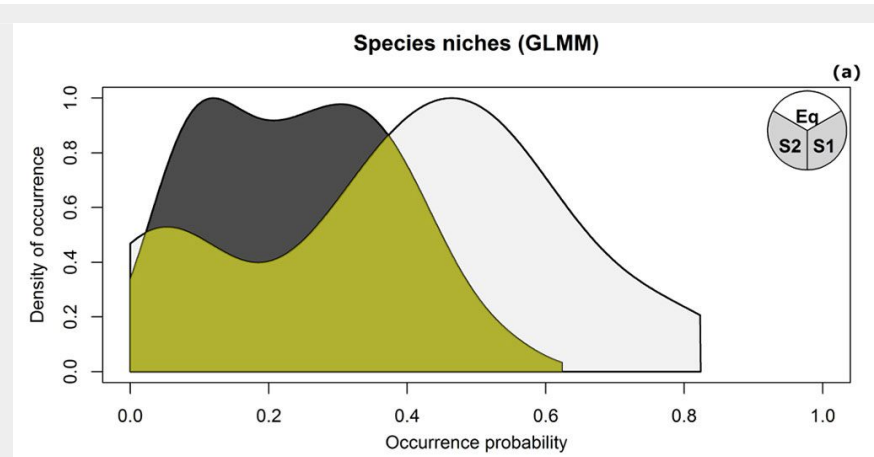

Species niches (OM)

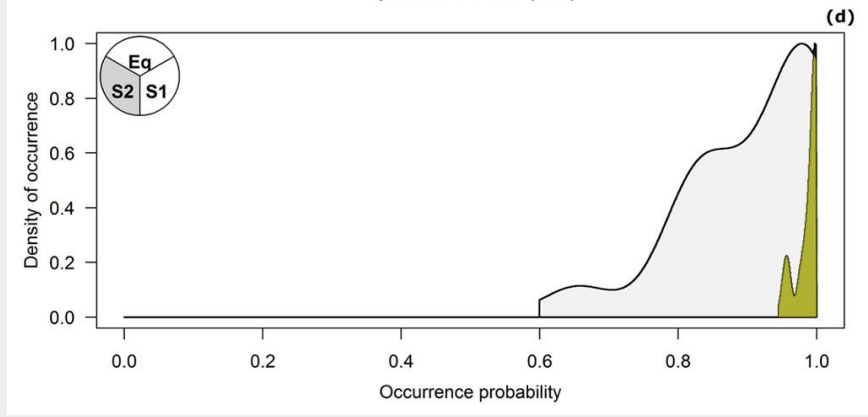

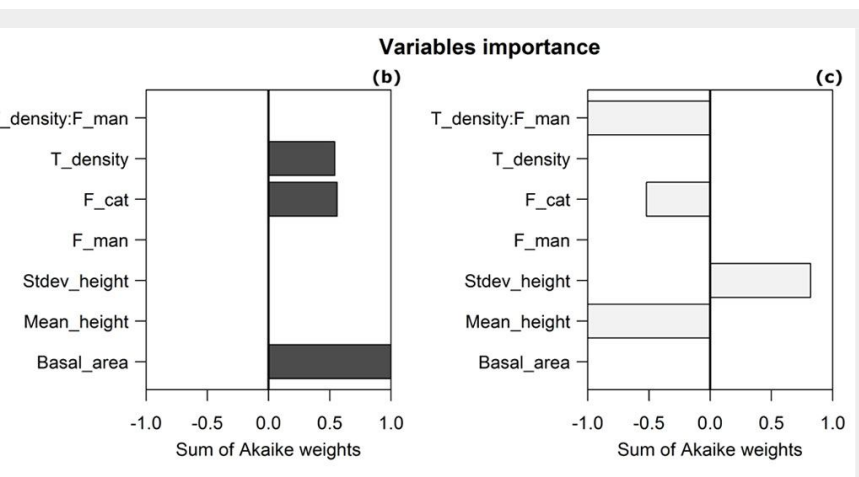

Variables importance

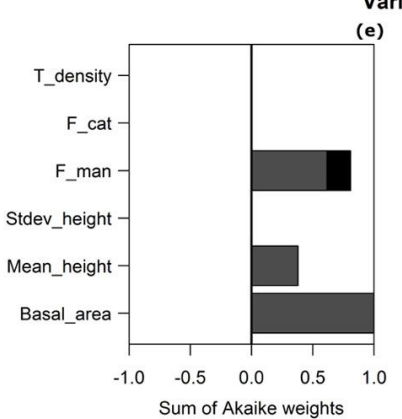

Fig. 3 - Models' outcomes. The two rows show results for GLMM and OM, respectively. First column depicts niches of edible (dark grey) and hazel (light grey) dormice calculated from GLMM (a) and OM (d) predictions. Yellow areas refer to niche overlap. Circles $(a, d)$ show the significant outcomes (white) of the equivalency and similarity tests. Bar plots on the right display variables importance for the two species calculated by $\operatorname{GLMM}(b, c)$ and OM (e, f), as the cumulative sum of Akaike weights over the top-ranked models. Only variables being selected in at least a half of the top-ranked models were included. For forest management ( $F$ man) two of the three levels are shown: high forests (dark grey) and coppices in transition (black). For forest category ( $F_{-}$cat) the level referring to "Turkey oak" category was displayed.

(Schoener's D = $0.26-$ Fig. 3d) yielded significant outcomes for both niche equivalency and similarity (i.e., niche 1 vs. niche 2 - Fig. 3a, Fig. 3d, Tab. 2).

For both species, overlap values calculated between GLMM predictions and OM detectabilities (i.e., $\mathrm{P}_{\text {occ }}$ vs. Det_) were higher than those calculated between GLMM predictions and OM occupancy (i.e., Pocc_vs. Psi_). Specifically, Schoener's D calculated for $\mathrm{P}_{\text {occ_Gglis }}$ vs. Det_Gglis were

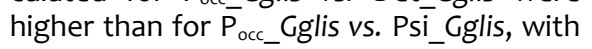

both tests resulting significant for the equivalency hypothesis (Warren et al. 2008 - Tab. 2). We found a similar pattern for

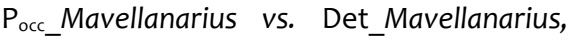
showing higher values of Schoener's $D$ than Pocc_Mavellanarius vs. Psi_Mavellanarius. In addition, $\mathrm{P}_{\text {occ }}$ Mavellanarius vs. Det_Mavellanarius failed to reject the null hypothesis of the equivalency test, i.e., the two niches were identical (Warren et al. 2008 - Tab. 2).

Finally, G. glis GLMM predictions by the first three sampling replicates $\left(\mathrm{P}_{\text {occ_ }}\right.$ Gglis rep 1-3) scarcely overlapped with the average predicted probability of occurrence

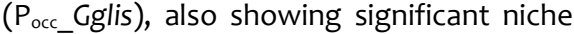
equivalency (i.e., not equivalent niches) and similarity tests (niche 2 vs. niche 1 ). $M$. avellanarius yielded a similar pattern, showing GLMM predictions by the first two replicates ( $P_{\text {occ_Mavellanarius_rep_1-2) as }}$ not equivalent to the average predicted occurrence probability ( $P_{\text {occ }}$ Mavellanarius Tab. 2). Only GLMM predictions from repli-
Fig. 4 - Maps of predicted detection probabilities for G. glis (left) and $M$. avellanarius (right). Detectability values, which range from 0 (blue) to 1 (red), were projected over the study area by spatializing the predictors selected in the top-ranked models (see also Appendix 3 in

Supplementary material). White (black) dots indicate presence (absence) sites.

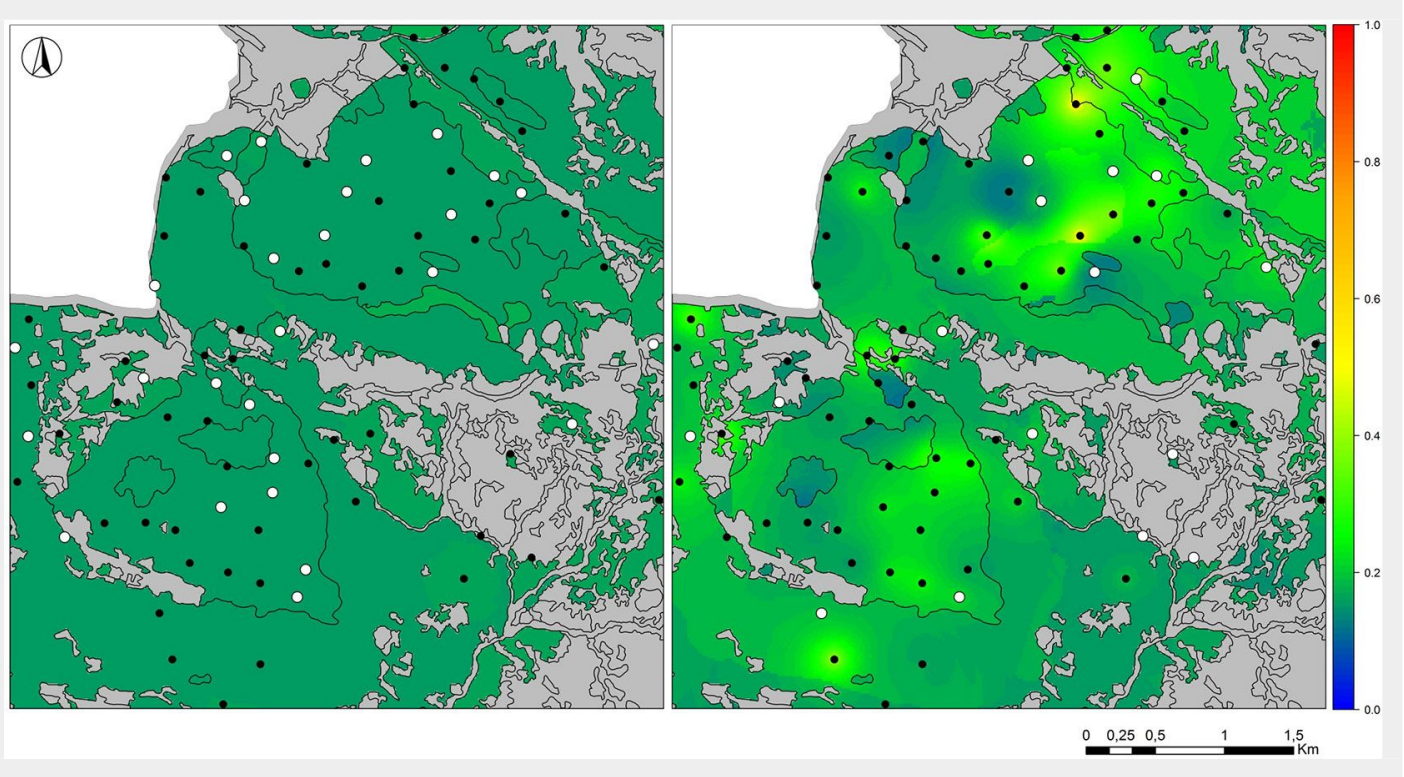


Tab. 2 - Results of niche overlap tests. (Schoener's D): niche overlap index; (Similarity1): similarity between the first species vs. the second; (Similarity2): similarity between the second species vs. the first; $\left(^{*}\right)$ : $p<0.05$; (ns): not significant.

\begin{tabular}{|c|c|c|c|c|c|}
\hline $\begin{array}{l}\text { Hypo- } \\
\text { thesis }\end{array}$ & Test & $\begin{array}{c}\text { Schoener's } \\
D\end{array}$ & $\begin{array}{l}\text { Equiva- } \\
\text { lency }\end{array}$ & $\begin{array}{c}\text { Similarity } \\
1\end{array}$ & $\begin{array}{c}\text { Similarity } \\
2\end{array}$ \\
\hline \multirow[t]{2}{*}{$\mathrm{H} 1$} & $\mathrm{P}_{\text {occ__Gglis vs. }} \mathrm{P}_{\text {occ__}}$ Mavellanarius & 0.41 & * & ns & ns \\
\hline & Psi_Gglis vs. Psi_Mavellanarius & 0.26 & * & * & ns \\
\hline \multirow[t]{4}{*}{$\mathrm{H} 2$} & Pocc_Gglis vs. Psi_Gglis & 0.00 & * & ns & ns \\
\hline & Pocc_Gglis vs. Det_Gglis & 0.47 & * & ns & ns \\
\hline & $\begin{array}{l}\text { Pocc_Mavellanarius vs. } \\
\text { Psi_Mavellanarius }\end{array}$ & 0.32 & * & ns & ns \\
\hline & $\begin{array}{l}\text { Pocc_Mavellanarius vs. } \\
\text { Det_Mavellanarius }\end{array}$ & 0.71 & ns & * & ns \\
\hline \multirow[t]{8}{*}{$\mathrm{H} 3$} & Pocc_Gglis vs. Pocc_Gglis_rep_1 & 0.08 & * & ns & * \\
\hline & Pocc_Gglis vs. Pocc_Gglis_rep_2 & 0.07 & * & ns & * \\
\hline & Pocc_Gglis vs. Pocc_Gglis_rep_3 & 0.15 & * & ns & * \\
\hline & 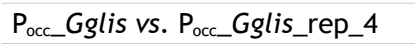 & 0.52 & ns & ns & ns \\
\hline & $\begin{array}{l}\text { Pocc_Mavellanarius vs. } \\
\text { Pocc_Mavellanarius_rep_1 }\end{array}$ & 0.02 & * & ns & ns \\
\hline & $\begin{array}{l}\text { Pocc_Mavellanarius vs. } \\
\text { Pocc_Mavellanarius_rep_2 } \text { _Ma }\end{array}$ & 0.00 & * & ns & ns \\
\hline & $\begin{array}{l}\text { Pocc_Mavellanarius vs. } \\
\text { Pocc_Mavellanarius_rep_3 }\end{array}$ & 0.08 & ns & * & * \\
\hline & $\begin{array}{l}\text { Pocc_Mavellanarius vs. } \\
\mathrm{P}_{\text {occ_Mavellanarius_rep_4 }}\end{array}$ & 0.33 & ns & * & * \\
\hline
\end{tabular}

cates 3 and 4 for $M$. avellanarius, and 4 for $G$. glis, resulted identical to the average predicted occurrence probability ( $\mathrm{P}_{\text {occ }}$ Tab. 2).

\section{Discussion}

Our results showed how niche overlap estimation corrected for imperfect detection was statistically more robust than classical models. This outcome is likely due to the fact that occurrence probabilities uncorrected for imperfect detection reflected the species detectability rather than its actual occurrence pattern. Being affected by this bias, occurrence probability values estimated by traditional presence/absence methods also led to a substantial niche underestimation, especially when relying on a low number of sampling replicates.

\section{Correcting for imperfect detection} increases significance in niche overlap tests

Niche overlap tests based on GLMM predictions showed significant outcomes only for the equivalency test. On the other hand, niche overlap computed on OM yielded significant outcomes for both niche equivalency and similarity. In particular, OM's niche similarity tests were significant only in one direction (from $G$. glis niche to $M$. avellanarius), indicating niche of $G$. glis to be completely included within that of $M$. avellanarius, but not vice versa. Such an asymmetric pattern suggests the edible dormouse and the hazel dormouse to be characterized by a narrow and a large niche respectively, with the first acting as habitat specialist and the latter as generalist, in accordance with several literature evidences. As a matter of fact, the edible dor- mouse is known to prefer forest stands with a continuous canopy cover (Capizzi et al. 2002, Juškaitis \& Siozinyte 2008), whereas the hazel dormouse is found in a variety of habitats, from deciduous woodland, to coppices, and other wooded areas with a dense understory layer dominated by shrubs (Sozio et al. 2016).

Such differences in forest habitat requirements between the two dormice species are strongly supported by OM predictions, whereas GLMM outcomes appeared less coherent with existing knowledge about the ecology of the studied species. Specifically, occupancy of G. glis was directly related with increasing stand basal area and mean tree height, with higher occupancy values in high forests and coppices in conversion. This evidence supports the findings that edible dormouse is an arboreal species which lives on the canopy of mature broadleaved (Cornils et al. 2017) or mature mixed woodlands (Capizzi et al. 2003). For M. avellanarius, occupancy was predominantly explained by low standard deviations of tree height, high tree densities and beech stands. These outcomes suggest $M$. avellanarius to prefer a wide variety of forests with different stand characteristics (Capizzi et al. 2002, Panchetti et al. 2007, Sozio et al. 2016), which in the study area include even-aged, highly dense stands (typical of the coppice management system) as well as beech forests predominantly managed as high forests (Frate et al. 2016). These differences in the ecological strategies of the two dormouse is coherent with their feeding habits. While the edible dormouse is known to feed mainly on beechnuts and adapted to yearly fluctuations in seed production (Bieber \& Ruf
2009), the hazel dormouse exhibited a wide dietary spectrum including berries, a variety of nuts and even insects eggs and larvae (Amori et al. 2008). It is important to note that seed production and availability are strongly influenced by forest management systems; for instance, the regeneration in high forests is mainly achieved by sexual reproduction, thus one of the main management goal is to ensure seed production by adopting long rotation cycles. On the contrary, in the coppice system the regeneration is ensured by the resprouting capacity of certain forest species: short rotation cycles (usually less than 20 years) reduce flowering and seed production (Ciancio et al. 2006). However, coppices have a higher number of understory species compared to high forests (Scolastri et al. 2017), including many shrubs species which offer a great variety of food resource for rodents, and in particular for hazel dormouse. In such a perspective, findings of the present study offer a methodological framework to assess forests naturalness and to explore possible effects of alternative forest management systems on stand structure, i.e., towards natural evolution and the establishment of old-growth forests (i.e., for beech forests - Chiavetta et al. 2012).

\section{Uncorrected occurrence probabilities} reflect species detectability instead of its occurrence

Our analyses showed that for both species, GLMM mostly estimated the species detectability rather than their actual occurrence pattern. This outcome was particularly evident for $M$. avellanarius for which GLMM predictions were statistically undistinguishable from the species detectability, i.e., the equivalency test failed to reject the null hypothesis. The bias introduced by imperfect detection in GLMM led this modelling technique to substantially spurious estimates of the two species niches and, consequently, to a lack of significance in their overlap pattern. Lahoz-Monfort et al. (2014) showed similar evidences for presence/absence and presence-only SDMs. In fact, these modelling approaches can wrongly identify a covariate influencing species detection as a covariate driving its occurrence, thus resulting in poor inference and predictions (Lahoz-Monfort et al. 2014). This argument would explain why, for M. avellanarius, GLMM predictions were statistically undistinguishable from the species detectability. For this species, occupancy and detectability are influenced by similar covariates, although through relationships with opposite signs (Fig. S2 in Supplementary material). This would have made GLMM particularly unable in discriminating between the covariates driving $M$. avellanarius occupancy and those influencing its detectability. This interpretation would be furtherly confirmed by the fact that GLMM occurrence probabilities and OM detectabilities for M. avellanarius are 
explained by approximately the same predictors through relationships with the same signs (except forest category - see Fig. 3 and Fig. S2). Such outcomes point out how modelling species occurrence without correcting for imperfect detection could lead to capture only where a species is more likely to be detected, making it difficult to distinguish between predictions that reliably reflect ecological processes and those that are related to detectability effects (Lahoz-Monfort et al. 2014, GuilleraArroita 2017). As a consequence, two species whose occurrence predictions would be affected by such kind of bias, would reveal an inconsistent and likely unreliable overlap pattern between their niches.

\section{Few sampling replicates lead to a niche} underestimation

It is noteworthy how GLMM predictions based on the first three (for $G$. glis) and the first two (for $M$. avellanarius) sampling replicates were mostly different from the average occurrence probability predicted by GLMM over all the four replicates. In particular, the statistical significance in niche equivalency tests for the first three replicates of $G$. glis indicated these niches to be non-identical to that calculated from the average occurrence probability over all the replicates. In addition, niche similarity tests for these three replicates were significant only in one direction (from $\mathrm{P}_{\text {occ_CGlis }}$ rep_1-3 niches to $P_{\text {occ_Cglis one). This asym- }}$ metry suggested that $G$. glis niches estimated by each of these sampling replicates represent only a subpart of that calculated from the average occurrence probability over all the replicates.

We found a similar result also for $M$. avellanarius, though involving only the first two sampling replicates, likely due to the overall higher detectability of such species compared to G. glis (Fig. 4). Such evidences point out how imperfect detection, besides leading GLMM to estimate species detectability rather than occurrence, provokes a substantial underestimation of species niche, by introducing a high number of false absences at occupied sites. A similar outcome was also highlighted for SDMs by Lahoz-Monfort et al. (2014) and could be explained considering that a high rate of false absences likely results in an incomplete sampling of the species niche, thus affecting niche estimation and predictions. Under this perspective, imperfect detection seems to affect niche estimation similarly to the bias introduced by the geographic truncation in sampling occurrence data. In fact, it is well documented how covering the entire species niche is crucial to assess niche overlap and change without bias (Raes 2012, Guisan et al. 2014). Specifically, an incomplete sampling of species niche may prevent capturing the full environmental variation under which a species is known to occur, often resulting in a niche underestimation (Raes 2012). Therefore, when geographic truncation leads to environmental truncation, assessment of niche overlap should be carefully considered (Guisan et al. 2014).

In light of the environmental truncation effect exerted by imperfect detection on niche overlap estimates, an adequate number of sampling replicates is highly advisable, also taking into account that differences in species detectability among sampling replicates covering different periods of the year may be a result of seasonal effects, e.g., climate (Mackenzie \& Royle 2005). For instance, the overall increase in detection probability observed from the first to the last sampling replicate, might be a consequence of an intensified activity to gather trophic resources as the cold season was approaching, leading the two dormice species to visit the sampling sites more frequently than during the first replicates (Sozio et al. 2016, Cornils et al. 2017). While our results strongly support a role by the number of sampling replicates to estimate niche overlap, we cannot exclude that alternative sampling protocols (e.g., one-per-stratum) might have yielded different outcomes from those showed here.

\section{Conclusions}

Our study emphasized how accounting for imperfect detection can improve the statistical significance and interpretability of niche overlap estimates based on occurrence data. Such approach allowed to identify alternative ecological strategies between the two forest dormice i.e., habitat generalist vs. habitat specialist. The edible dormouse exhibited a strict link with high forests, while the hazel dormouse showed to prefer a wide variety of forest types. These differences could be mainly due to the different feeding habits of the two species, which are in turn affected by the forest management system. In a forest management context, an accurate quantification of niche overlap provides useful information to assess the effects of different management practices on the occurrence of these arboreal species. For instance, a management strategy oriented at promoting high forests would likely favor both the specialist edible dormouse and the generalist hazel dormouse, as the two species share a significant portion of their niches corresponding to forests with these characteristics. On the other hand, practices enhancing forest stands with different characteristics would primarily have a positive effect on the occurrence of $M$. avellanarius and not necessarily on $G$. glis.

\section{Acknowledgments}

We thank Giorgio Matteucci and Bruno De Cinti (National Research Council of Italy) who promoted our research and Carlo Rondinini ("Sapienza" University of Rome, Italy) for his support and advices. We wish to thank Rodolfo Bucci, Andrea Mancinelli, Maurizio Di Marco, Nicolò Carlini, Flaminia Cesaretti, Carlo Carozza, Paolo Perrella, Michele Carnevale, Carmine Cioc- ca, Domenico Trella and Genuino Potena for their support and assistance in various phases of the fieldwork as well as for crafting nest boxes.

This research was partly granted by the ManFor C.BD. project (LIFEog/ENV/IT/0oo 078). CP field work was supported by a project funded by Regione Abruzzo within the Piano di Sviluppo Rurale 2007-2013, aimed at drawing up the management plan of Natura 2000 site IT7110104. Three anonymous referees provided valuable comments that significantly improved the manuscript.

\section{Authors' contribution}

$\mathrm{CP}$ and MDF have equally contributed to this paper.

\section{References}

Amori G, Contoli L, Nappi A (2008). Fauna d'Italia. Mammalia II. Erinaceomorpha, Soricomorpha, Lagomorpha, Rodentia [Fauna of Italy. Mammalia II. Erinaceomorpha, Soricomorpha, Lagomorpha, Rodentia]. Edizioni Calderini - II Sole 24 ORE, Edagricole, Bologna, Italy, pp. 736. [in Italian]

Araya YN, Silvertown J, Gowing DJ, McConway KJ, Peter Linder H, Midgley G (2011). A fundamental, eco-hydrological basis for niche segregation in plant communities. New Phytologist 189: 253-258. - doi: 10.1111/j.1469-8137.2010.034 75. $\mathrm{x}$

Bailey LL, Mackenzie DI, Nichols JD (2014). Advances and applications of occupancy models. Methods in Ecology and Evolution 5: 1269-1279. - doi: 10.1111/2041-210X.12100

Barton K (2018). MuMIn: multi-model inference (version 1.40.4). Web site. [online] URL: http:// cran.r-project.org/web/packages/MuMIn/MuMI n.pdf

Bates D, Mächler M, Bolker BM, Walker SC (2015). Fitting linear mixed-effects models using Ime4. Journal of Statistical Software 67: 148. - doi: 10.18637/jss.v067.i01

Bieber C, Ruf T (2009). Habitat differences affect life history tactics of a pulsed resource consumer, the edible dormouse (Glis glis). Population Ecology 51: 481-492. - doi: 10.1007/s10144009-0140-x

Blasi C, Fortini P, Grossi G, Presti G (2005). Faggete e cerrete mesofile nell'Alto Molise [Beech and mesophilous Quercus cerris woodlands in Alto Molise (central Italy)]. Fitosociologia 42: 67-81. [in Italian] [online] URL: http:// www.scienzadellavegetazione.it/sisv/documen ti/Articolo/pdf/128.pdf

Bright PW, Morris PA (1991). Ranging and nesting behaviour of the dormouse, Muscardinus avellanarius, in diverse low-growing woodland. Journal of Zoology 224: 177-190. - doi: 10.1111/ j.1469-7998.1991.tbo4797.x

Bright PW, Morris PA (1992). Ranging and nesting behaviour of the dormouse Muscardinus avellanarius, in coppice-with-standards woodland. Journal of Zoology 226: 589-600. - doi: 10.1111/j.1469-7998.1992.tbo7502.x

Bright PW, Mitchell P, Morris PA (1994). Dormouse distribution: survey techniques, insular ecology and selection of sites for conservation. Journal of Applied Ecology 31: 329-339. - doi: 


\section{$10.2307 / 2404547$}

Broennimann O, Fitzpatrick MC, Pearman PB, Petitpierre B, Pellissier L, Yoccoz NG, Thuiller W, Fortin MJ, Randin C, Zimmermann NE, Graham $\mathrm{CH}$, Guisan A (2012). Measuring ecological niche overlap from occurrence and spatial environmental data. Global Ecology and Biogeography 21: 481-497. - doi: 10.1111/j.1466-8238.2011.0 0698.x

Broennimann O, Di Cola V, Petitpierre B, Breiner F, D'Amen $M$, Randin C, Engler R, Hordijk W, Pottier J, Di Febbraro M, Pellissier L, Pio D, Mateo RG, Dubuis A, Scherrer D, Maiorano L, Psomas A, Ndiribe C, Salamin N, Zimmermann N, Guisan A (2017). "ecospat”: spatial ecology miscellaneous methods (version 2.2.0). Web site. [online] URL: http://cran.r-project.org/web/pac kages/ecospat/ecospat.pdf

Burnham KP, Anderson DR (2002). Model selection and multimodel inference: a practical information - theoretic approach $\left(2^{\text {nd }}\right.$ edn). SpringerVerlag, New York, USA, pp. 488. - doi: 10.1007/ b97636

Burnham KP, Anderson DR, Huyvaert KP (2011). AIC model selection and multimodel inference in behavioral ecology: some background, observations, and comparisons. Behavioral Ecology and Sociobiology 65: 23-35. - doi: 10.1007/ s00265-010-1029-6

Capizzi D, Battistini M, Amori G (2002). Analysis of the hazel dormouse, Muscardinus avellanarius, distribution in a Mediterranean fragmented woodland. Italian Journal of Zoology 69: 25-31. - doi: 10.1080/11250000209356434

Capizzi D, Battistini M, Amori G (2003). Effects of habitat fragmentation and forest management on the distribution of the edible dormouse Glis glis. Acta Theriologica 48: 359-371. - doi: 10.1007 /BF03194175

Chen G, Kéry M, Plattner M, Ma K, Gardner B (2013). Imperfect detection is the rule rather than the exception in plant distribution studies. Journal of Ecology 101: 183-191. - doi: 10.1111/136 5-2745.12021

Chiavetta U, Sallustio L, Garfì V, Maesano M, Marchetti M (2012). Classification of the oldgrowthness of forest inventory plots with dissimilarity metrics in Italian National Parks. European Journal of Forest Research 131: 1473-1483. - doi: 10.1007/s10342-012-0616-7

Ciancio O, Corona P, Lamonaca A, Portoghesi L, Travaglini D (2006). Conversion of clearcut beech coppices into high forests with continuous cover: a case study in central Italy. Forest Ecology and Management 224: 235-240. - doi: 10.1016/j.foreco.2005.12.045

Cornils JS, Hoelzl F, Rotter B, Bieber C, Ruf T (2017). Edible dormice (Glis glis) avoid areas with a high density of their preferred food plant - the European beech. Frontiers in Zoology 14: 1-10. - doi: 10.1186/s12983-017-0206-0

Fiske IJ, Chandler RB (2011). "unmarked”: an R package for fitting hierarchical models of wildlife occurrence and abundance. Journal of Statistical Software 43: 1-23. - doi: 10.18637/jss. v043.i10

Frate L, Carranza ML, Garfì V, Di Febbraro M, Tonti D, Marchetti M, Ottaviano M, Santopuoli G, Chirici G (2016). Spatially explicit estimation of forest age by integrating remotely sensed data and inverse yield modeling techniques.
iForest 9: 63-71. - doi: 10.3832/ifor1529-008

Gasparini P, Tabacchi G (2011). L'Inventario Nazionale delle Foreste e dei serbatoi forestali di Carbonio INFC 2005. Secondo inventario forestale nazionale italiano. Metodi e risultati [National inventory of forests and forest carbon sinks INFC 2005. Second Italian national forest inventory. Methods and results]. Ministero delle Politiche Agricole, Alimentari e Forestali, Corpo Forestale dello Stato, Consiglio per la Ricerca e la Sperimentazione in Agricoltura, Unità di ricerca per il Monitoraggio e la Pianificazione Forestale, Edagricole, Bologna, Italy, pp. 1-653. [in Italian]

Green AW, Bailey LL, Nichols JD (2011). Exploring sensitivity of a multistate occupancy model to inform management decisions. Journal of Applied Ecology 48: 1007-1016. - doi: 10.1111/j.13652664.2011.01995.x

Gregory SD, MacDonald DW (2009). Prickly coexistence or blunt competition? Opuntia refugia in an invaded rodent community. Oecologia 159: 225-236. - doi: 10.1007/s00442-008-1196-6

Grinnell J (1917). The niche-relationships of the California Thrasher. The Auk 34: 427-433. - doi: 10.2307/4072271

Guillera-Arroita G (2017). Modelling of species distributions, range dynamics and communities under imperfect detection: advances, challenges and opportunities. Ecography 40: 281295. - doi: 10.1111/ecog.02445

Guisan A, Petitpierre B, Broennimann O, Daehler C, Kueffer C (2014). Unifying niche shift studies: insights from biological invasions. Trends in Ecology and Evolution 29: 260-269. - doi: 10.101 6/j.tree.2014.02.009

Hutchinson GE (1957). Concluding remarks. Cold Spring Harbor Symposia on Quantitative Biology 22: 415-427. - doi: 10.1101/SQB.1957.022.01. 039

Johnson PCD, Barry SJE, Ferguson HM, Müller P, Schielzeth H (2015). Power analysis for generalized linear mixed models in ecology and evolution. Methods in Ecology and Evolution 6: 133142. - doi: 10.1111/2041-210X.12306

Juškaitis R, Siozinyte V (2008). Habitat requirements of the common dormouse (Muscardinus avellanarius) and the fat dormouse (Glis glis) in mature mixed forest in Lithuania. Ekológia 27: 143-151. [online] URL: http://www.researchgate. net/publication/256094022

Kirchheimer B, Schinkel CFF, Dellinger AS, Klatt $S$, Moser D, Winkler M, Lenoir J, Caccianiga $M$, Guisan A, Nieto-Lugilde D, Svenning JC, Thuiller W, Vittoz P, Willner W, Zimmermann NE, Hörandl E, Dullinger S (2016). A matter of scale: apparent niche differentiation of diploid and tetraploid plants may depend on extent and grain of analysis. Journal of Biogeography 43: 716-726. - doi: 10.1111/jbi.12663

Lahoz-Monfort JJ, Guillera-Arroita G, Wintle BA (2014). Imperfect detection impacts the performance of species distribution models. Global Ecology and Biogeography 23: 504-515. - doi: 10.1111/geb.12138

Lombardi F, Lasserre B, Tognetti R, Marchetti M (2008). Deadwood in relation to stand management and forest type in Central Apennines (Molise, Italy). Ecosystems 11: 882-894. - doi: 10.1007/s10021-008-9167-7

MacKenzie DI, Nichols JD, Lachman GB, Droege
S, Royle JA, Langtimm CA (2002). Estimating site occupancy rates when detection probabilities are less than one. Ecology 83: 2248-2255. doi: 10.1890/0012-9658(2002)083[2248:ESORW D]2.0.CO;2

Mackenzie DI, Royle JA (2005). Designing occupancy studies: general advice and allocating survey effort. Journal of Applied Ecology 42: 1105-1114. - doi: 10.1111/j.1365-2664.2005.01098.x McCullagh P, Nelder JA (1989). Generalized Linear Models. CRC Monographs on Statistics and Applied Probability, Chapman and Hall London, New York, USA pp. 532. - doi: 10.1007/978-1-48 99-3242-6

McGill BJ, Etienne RS, Gray JS, Alonso D, Anderson MJ, Benecha HK, Dornelas M, Enquist BJ, Green JL, He F, Hurlbert AH, Magurran AE, Marquet $\mathrm{PA}$, Maurer BA, Ostling A, Soykan $\mathrm{CU}$, Ugland KI, White EP (2007). Species abundance distributions: moving beyond single prediction theories to integration within an ecological framework. Ecology Letters 10: 995-1015. - doi: 10.1111/j.1461-0248.2007.01094.x

Mortelliti A, Santulli Sanzo G, Boitani L (2009). Species' surrogacy for conservation planning: caveats from comparing the response of three arboreal rodents to habitat loss and fragmentation. Biodiversity and Conservation 18: 11311145. - doi: 10.1007/s10531-008-9477-2

Mortelliti A, Crane M, Okada S, Lindenmayer DB (2015). Marsupial response to matrix conversion: results of a large-scale long-term "natural experiment" in Australia. Biological Conservation 191: 60-66. - doi: 10.1016/j.biocon.2015.06. 015

Nagelkerke NJD (1991). A note on a general definition of the coefficient of determination. Biometrika 78: 691-692. - doi: 10.1093/biomet/78.3. 691

Nakagawa S, Freckleton RP (2011). Model averaging, missing data and multiple imputation: a case study for behavioural ecology. Behavioral Ecology and Sociobiology 65: 103-116. - doi: 10.1007/s00265-010-1044-7

Nakagawa S, Schielzeth H, Hara RB (2013). A general and simple method for obtaining $R^{2}$ from generalized linear mixed-effects models. Methods in Ecology and Evolution 4: 133-142. doi: 10.1111/j.2041-210x.2012.00261.x

Panchetti F, Sorace A, Amori G, Carpaneto GM (2007). Nest site preference of common dormouse (Muscardinus avellanarius) in two different habitat types of Central Italy. Italian Journal of Zoology 74: 363-369. - doi: 10.1080/11250000 701588224

R Development Core Team (2018). R: a language and environment for statistical computing. $R$ Foundation for Statistical Computing, Vienna, Austria. [online] URL: http://www.r-project.org/ Raes N (2012). Partial versus full species distribution models. Natureza and Conservação 10: 127138. - doi: 10.4322/natcon.2012.020

Rota CT, Fletcher RJ, Evans JM, Hutto RL (2011). Does accounting for imperfect detection improve species distribution models? Ecography 34: 659-670. - doi: 10.1111/j.1600-0587.2010.0643 $3 . \mathrm{x}$

Russo D, Di Febbraro M, Cistrone L, Jones G, Smeraldo S, Garonna AP, Bosso L (2015). Protecting one, protecting both? Scale-dependent ecological differences in two species using 
dead trees, the rosalia longicorn beetle and the barbastelle bat. Journal of Zoology 297: 165175. - doi: 10.1111/jzo.12271

Schoener TW (1970). Nonsynchronous spatial overlap of lizards in patchy habitats. Ecology 51: 408-418. - doi: 10.2307/1935376

Scolastri A, Cancellieri L, locchi M, Cutini M (2017). Old coppice versus high forest: the impact of beech forest management on plant species diversity in central Apennines (Italy). Journal of Plant Ecology 10: 271-280. - doi: 10.10 93/jpe/rtw034

Sozio G, lannarilli F, Melcore I, Boschetti $M$, Fipaldini D, Luciani M, Roviani D, Schiavano A, Mortelliti A (2016). Forest management affects individual and population parameters of the hazel dormouse Muscardinus avellanarius. Mammalian Biology 81: 96-103. - doi: 10.1016/j.mam bio.2014.12.006

Vizzarri M, Chiavetta U, Chirici G, Garfì V, Bastrup-Birk A, Marchetti M (2015). Comparing multisource harmonized forest types mapping: a case study from central Italy. iForest 8: 59-66. - doi: 10.3832/ifor1133-007

Warren DL, Glor RE, Turelli M (2008). Environmental niche equivalency versus conservatism: quantitative approaches to niche evolution. Evolution 62: 2868-2883. - doi: 10.1111/j.1558-56 46.2008.00482.x

Zuur AF, leno EN, Elphick CS (2010). A protocol for data exploration to avoid common statistical problems. Methods in Ecology and Evolution 1: 3-14. - doi: 10.1111/j.2041-210X.2009.0000 1. $\mathrm{x}$

Zuur AF, Hilbe JM, leno EN (2013). A beginner's guide to GLM and GLMM with R: frequentist and Bayesian perspective for ecologists. Highland Statistics Limited, Newburgh, USA, pp. 253.

\section{Supplementary Material}

Appendix 1 - Details on the hair identification protocol.

Appendix 2 - Description of the 12 explanatory variables measured and estimated at each sampling plot.

Appendix 3 - Details on the spatialization procedure.
Tab. S1 - Summary of presence (1) and absence (0) of two arboreal rodent species (G. glis and M. avellanarius) in the 83 sampling sites.

Tab. S2 - Top-ranked GLMMs derived from the model selection procedure. $\mathrm{W}$ indicates the Akaike weight of each model.

Tab. S3 - Top-ranked OMs derived from the model selection procedure.

Fig. S1 - First (second) row depicts maps of predicted occurrence probabilities for $G$. glis (left) and $M$. avellanarius (right) by GLMM (OM).

Fig. S2 - Detectability variables importance for edible (dark grey) and hazel (light grey) dormice, as the cumulative sum of Akaike weights over the top-ranked models.

Link: Paniccia_2738@supplo01.pdf 